\title{
REMOTE SEnSING-BASEd GeOSTATISTICAL Modeling FOR CONIFEROUS FOREST INVENTORY AND CharaCterization
}

\author{
MARK E. JAKUBAUSKAS $\downarrow$ EDWARD A. MARTINKO $\uparrow$ KEVIN P. PRICE \\ KANSAS APPLIED REMOTE SENSING (KARS) PROGRAM \\ UNIVERSITY OF KANSAS $\downarrow$ LAWRENCE
}

\section{$\uparrow \quad$ INTRODUCTION}

Resource managers of private and public forests are often faced with a host of questions on forest extent, condition, and change in the course of land management. With more than 700 million acres of land covered by forest in the United States, the task of mapping and inventorying forested lands is a challenging one. Detailed and accurate maps of forest condition and structure are a necessity for rigorous ecosystem management. Forest maps are a fundamental information source for fire behavior modeling, animal habitat management, prediction and mapping of forest insect infestations, and plant and animal biodiversity assessment.

Digital images acquired by earth imaging satellites are being used to help forest managers provide this information. Satellite images, when analyzed using advanced geostatistical techniques, can produce information on forest condition and structure, information that can be used to help answer questions such as those posed above. Satellite imagery has been used for many years to map land cover in forested regions, but natural resource managers are also starting to use remotely sensed satellite imagery to calculate the age, density, species, and successional state of forests under their care.

In May 1999, the Kansas Applied Remote Sensing (KARS) Program at the University of Kansas was selected by NASA Earth Science Enterprise Applications Division to develop methods that use remote-sensing data and advanced geostatistical methods to create maps of forest age and successional state, or "cover types," and of forest biophysical factors, including density, biomass, leaf area, basal area, and height. By calibrating remotely sensed multispectral data with a small number of ground measurements, characteristics of the forest measured at sample points can be extrapolated across a large geographic region. This has significant advantages for forest management, especially when forests are in remote or inaccessible locations.

The goal of this research is to develop new methods for the analysis of forest canopy structure, secondary forest regrowth, and forest fire history that take advantage of both the spectral and spatial correlation of ground phenomena and remotely sensed information.

\section{$\downarrow \quad$ PREVIOUS RESEARCH}

Past research topics have included characterization and modeling of lodgepole pine seral stages (Jakubauskas and Price, 1997; Jakubauskas, 1996a), analysis of image texture and forest regeneration (Jakubauskas, 1997), effects of insect damage on spectral response in a successional continuum (Price and Jakubauskas, 1998), investigation of forest structure / age class in Yellowstone and Grand Teton National Parks (Jakubauskas and Price, 2000; Jakubauskas, 1996b), and generating forest canopy structure models from remotely sensed data (Jakubauskas et al, 2001). 


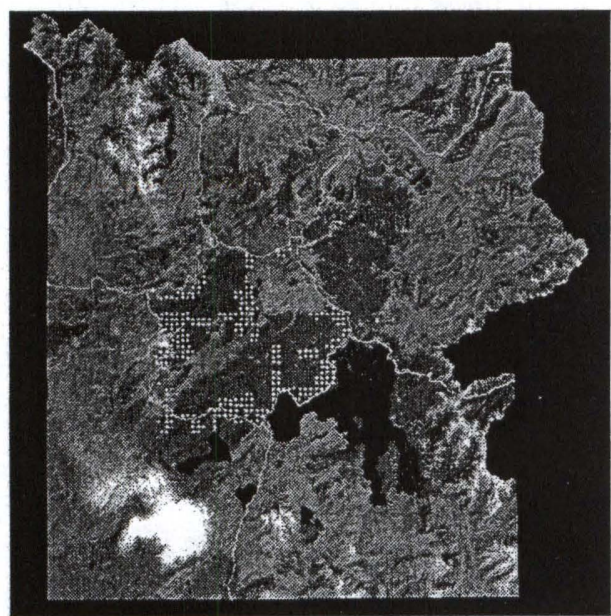

Figure 1. Landsat 7 ETM+ image of Yellowstone National Park, July 13, 1999. Sample points for the study within the Central Plateau are indicated by white dots. The Grand Loop Road appears as yellow lines.

Integrating satellite imagery and field data for regional forest inventory

A single sample point, or a set of sample points distributed about an area provide information only about the area immediately adjacent to a given point, and provide no information about unsampled locations between points. Characteristics of the forest measured at a sample point, therefore, may not truly indicate the range or variability in sample values within an area. This potentially can lead to erroneous forest management decisions based on incomplete or unrepresentative data. Field-sampled data are often expensive and time-consuming to collect and analyze, and the inaccessibility of sample sites, due to topography or other conditions, may further limit the size of the data set.

Remotely sensed data, in contrast, are a spatially explicit sample of an area, but must be related to field data by some means in order to produce a useful product. Historically, this integration of field and satellite data was performed on a qualitative basis: data from field samples were used to visually identify stands with certain characteristics on a satellite image or air photo, or used to identify clusters of spectrally similar pixels in a digital image that had been clustered by a computer into discrete classes. Simple statistics, such as correlation and regression, have been used in remote sensing for many years to describe the relationship between the amount of light reflected by an point or location, and some property or attribute of that area, whether that be biomass or leaf area or canopy characteristics. By c alibrating r emotely s ensed data with field-sampled ground measurements, forest characteristics measured at independent points can be mapped across a large geographic region, including areas that have not been field-sampled.

Remotely sensed data can be integrated with information collected in field sampling by several means. Researchers have used correlation or regression analysis to study relationships between spectral reflectance and coniferous forest structural factors, including basal area and biomass, crown closure, diameter at breast height, height and density, forest age, and leaf area index. Regression equations produced by statistical analysis of spectral and forest characteristics can be applied on a pixel-by-pixel basis to a digital remotely sensed image to produce forest maps, such as a map of forest age. A more sophisticated method for integrating satellite and field data u ses g eostatistics. Geostatistics, sometimes also referred to as spatial statistics, are an advanced geographic analysis technique that take into account the characteristics of the area surrounding a point of interest to make more precise and accurate estimates.

\section{$\downarrow \quad$ STUDY AREA}

Initial model development will focus on the lodgepole pine (Pinus contorta var latifolia) forest of the Central Plateau region of Yellowstone, where we have been conducting forest research for nearly a decade. Elevations range between 2100 and 2600 meters, with occasional streams bisecting the gently rolling uplands. The majority of the Central Plateau vegetation is classified by Despain (1990) into the subalpine fir/grouse whortleberry (Abies lasiocarpa/Vaccinium scoparium) habitat type, with much of the habitat type consisting of lodgepole pine forest in a mosaic of successional stages, or cover types. The Despain cover type classification for Yellowstone uses a letter code to designate the species (LP = lodgepole pine) and a numerical code $(0,1,2,3)$ to indicate the relative stage of development of the forest stand.

\section{Field Sampling Methods}

Field sampling during summer 1999 and 2000 has been directed toward acquiring a set of forest structural and biophysical parameters in the Central 
Plateau of Yellowstone National Park at two spatial scales. Broad-scale sampling was performed at points on a 1 $\mathrm{km}$ grid interval corresponding to major UTM easting/northing intersections. Intensive sampling was performed at three sets of fine grids with points placed at $100 \mathrm{~m}$ intervals, nested within the coarse sampling grid (50 points per intensive grid; 150 points total). The three intensive grid sites were located in areas dominated by each of three distinct lodgepole pine cover types: LP0 (early successional, 0-70 years postfire, areas regenerating from the 1988 fires); LP1 (mid-successional, approximately $70-150$ years postfire); and LP3 (late successional, approximately 250-350 years postfire). Field sites were located on the sampling grids using GPS units. Given the large number of sites to be sampled to achieve the necessary dense network of points, plotless methods for calculation of live basal area and tree height were employed. At each site, live basal area was determined for each species using cruising prisms. Tree heights was calculated for the two tallest trees in each of the four quadrants defined by the intersection of a northsouth line and a east-west line at the sampler's feet. Rangefinders were used to determine the distance to the base of each tree sampled for height, and clinometers were used to measure the angle to the base and top of each tree. Tree heights were calculated using trigonometric equations. Canopy density was determined at each site using densiometers. Leaf area index (LAI) was measured using a line quantum sensor. Aboveground green biomass is derived from basal area using allometric equations specific to lodgepole pine.

\section{Satellite multispectral imagery}

Landsat 7 Enhanced Thematic Mapper (ETM+) satellite multispectral data were acquired for the park on July 13, August 14, and September 15, 1999. These three data sets are available to interested researchers working in Yellowstone at an online image data archive http://www.kars.ukans.edu/forest/landsat 7.html. Data have been converted to radiance, topographically adjusted, and converted to radiance. Additional data to be acquired during the 2001 field season include additional Landsat 7 ETM+ imagery, EO-1/Hyperion hyperspectral data, Space Imaging IKONOS $4.0 \mathrm{~m}$ multispectral data, and airborne digital multispectral camera imagery with a spatial resolution of 1.0 meter.

\section{Results AND Progress to DATE}

A total of 433 points were sampled in the
Central Plateau of Yellowstone in 1999 and 2000 (50 points each in the three intensive grids, 283 points on the extensive grid) (Figure1). Geostatistical analysis of the point and image data is ongoing. Kriged estimates of forest biophysical parameters have been completed, and cokriged estimates of forest parameters, using the field data and an $N$ ormalized $D$ ifference $V$ egetation Index (NDVI) transformation of the satellite imagery are in progress.

\section{Literature Cited}

Despain, D.G. 1990. Yellowstone Vegetation: Consequences of Environment and History in a Natural Setting. Roberts Rinehart, Boulder, Colorado. $239 \mathrm{p}$

Jakubauskas, M.E., Martinko, E.A., Price, K.P., and Moskal, L.M. 2001. Regional forest inventory by geostatistical integration of satellite imagery and field-sampled data. 2001 ASPRS Annual Meeting, St. Louis, MO.

Jakubauskas, M.E. 1997. Effects of forest regeneration on texture in Landsat Thematic Mapper imagery. Canadian Journal of Remote Sensing 23(3):251-257

Jakubauskas, M.E. 1996a. Thematic Mapper characterization of lodgepole pine seral stages in Yellowstone National Park, USA. Remote Sensing of Environment, 56:118-132.

Jakubauskas, M.E. 1996b. Canonical correlation analysis of coniferous forest spectral and biotic relationships. International Journal of Remote Sensing, 17(12):2323-2332.

Jakubauskas, M.E. and Price, K.P. 2000. Regressionbased estimation of lodgepole pine forest age from Landsat Thematic Mapper Data. Geocarto International 15(1):1-6.

Jakubauskas, M.E. and Price, K.P. 1997. Empirical relationships between biotic and spectral factors of Yellowstone lodgepole pine forests. Photogrammetric Engineering and Remote Sensing 63(12):1375-1381

Price, K.P., and Jakubauskas, M.E. 1998. Spectral retrogression and insect damage in lodgepole pine forests. International Journal of Remote Sensing 19(8):1627-1632. 